\title{
SOLIDARIDAD Y SIGNOS DE IDENTIDAD DE LA POBLACIÓN MORISCA DE ALMERÍA
}

Dolores Segura del Pino

El tema de la solidaridad morisca y los signos de identidad propios de esta comunidad, aunque es muy conocido en su aspecto general y está constatado en diversos estudios locales y temáticos, por su propio carácter privado, al desarrollarse dentro del ámbito de las relaciones personales, presenta aún muchos interrogantes: ¿la cohesión de linaje es uniforme en toda la comunidad morisca? ¿La posición social y económica facilita esta cohesión? ¿Las presiones a que están sometidos postergan sus tradiciones y costumbres?

Para llegar a conocer alguna de estas cuestiones vamos a centrarnos en el marco urbano y rural de la ciudad de Almería y su vega, desde la conquista de la ciudad en 1489 hasta la expulsión de los moriscos en 1570. Es, por tanto, un estudio local de la comunidad morisca de Almería.

La principal fuente documental utilizada son los protocolos notariales de la época morisca conservados en el Archivo Histórico Provincial de Almería ${ }^{1}$, especialmente los testamentos, cartas de dote, donaciones y otras escrituras en las que se entrevé, unas veces de forma clara y otras de forma sutil, la pervivencia de los vínculos de los moriscos a su comunidad de fe, o sea, al espíritu de la aljama. No obstante, esta documentación es fragmentaria, ya que el primer protocolo conservado es del año 1519 y la mayoría de los protocolos consultables están incompletos; por tanto, esta fuente sólo

* Doctora en Historia Medieval. Instituto de Estudios Almerienses.

1. Con esta finalidad se ha consultado la documentación siguiente: Protocolos de Alonso de Palenzuela: 1519 (Pr. 1); 1520 (Pr. 2); 1524 (Pr. 7, faltan los meses de abril a septiembre); 1525 (Pr. 8, falta de enero a septiembre); 1528 (Pr. 10 y 11, faltan los meses de agosto y septiembre); 1531 (Pr. 13, faltan enero, abril y junio). Protocolos de Pedro Gallego: 1542 (Pr. 38). Diego López de Badajoz: 1544 (Pr. 40, contiene julio y diciembre); 1545 (Pr. 40); 1546 (Pr. 41); 1550 y 1551 (Pr. 44); 1555 (Pr. 48); 1556 (Pr. 49); 1557 (Pr. 50); 1559 (Pr. 51). Cosme de Quevedo: 1561 (Pr. 65, falta diciembre); 1564 (Pr. 69). Gaspar de Gallegos: 1559, 1560, 1561 (Pr. 79); 1565 (Pr. 82). Alonso de Medrano: 1566 (Pr. 85). 
permite una aproximación aleatoria. A pesar de todo, la documentación notarial es de una riqueza inmensa y constituye una fuente fundamental para conocer este periodo ${ }^{2}$.

Como ya ha observado Bernard Vincent, existen "situaciones extremadamente diversas en el espacio y cambiantes en el tiempo en función de la cohesión de los grupos locales y de la política aplicada por la sociedad dominante"3.

Almería es una provincia pobre, las comunicaciones son malas y peligrosas por mar y por tierra, realmente está muy lejos de las autoridades granadinas y hasta la laxitud de su clero es motivo de queja en la Instrucción dada por el arzobispo de Granada, don Gaspar de Avalos, al canónigo

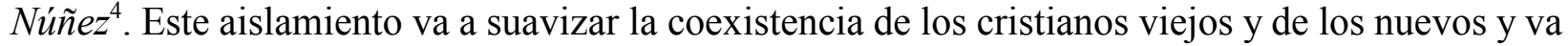
a favorecer la pervivencia cultural y los lazos de solidaridad familiar y de vecindario de los moriscos almerienses.

\section{LA SOCIEDAD URBANA Y RURAL.}

\section{LAS AGRUPACIONES FAMILIARES}

La orden de expulsión de los mudéjares de la ciudad de Almería en 1490 y la primera repoblación provoca que un número considerable de vecinos abandone sus casas y vaya a vivir a la vega y a las alquerías cercanas del valle del río de Almería; sin embargo, son muchos los que siguen viviendo en la ciudad. En el censo de $1561^{5}$ se cuentan alrededor de 300 vecinos moriscos; en el apeo de $1572^{6}$ la cifra oscila en torno a 257 vecinos. Desplazados de sus antiguas viviendas en el núcleo urbano, se concentraron en la parte

2. Basándose en esta misma fuente documental, destacan los estudios sobre los moriscos de Nicolás CABRILLANA CIÉZAR, publicados en diferentes artículos entre los años 1975 y 1978, destacando finalmente su obra Almería morisca, Granada, Universidad de Granada, 1982. A este tema ha dedicado también el padre J.A. TAPIA GARRIDO parte de su extensa obra. Entre los estudios más recientes se encuentran los realizados por Bernard VINCENT, concretamente: «50.000 moriscos almerienses», Coloquio Almería entre Culturas (siglos XIII-XVI), ponencia, Almería, I.E.A., 1990, pp. 489-514. Antonio MUÑOZ BUENDIA: «Supervivencia de la población morisca en Almería después de la expulsión de 1570: ejemplo de algunas familias», en Hespérides, IX Congreso de Profesores-Investigadores, El Ejido, 1990, pp. 503-536. E. PEZZI: Los moriscos que no se fueron, Almería, 1991.

3. A. DOMÍNGUEZ ORTIZ y B. VINCENT, Historia de los moriscos. Vida y tragedia de una minoría. Revista de Occidente, Madrid, 1978, p. XXX; B. VINCENT, «50.000 moriscos almerienses»...

4. A. Gallego Burín y A. GÁmir SAndoval, Los moriscos del Reino de Granada según el Sínodo de Guadix de 1554, ed. facsímil, Granada, 1996. Apéndice documental n. ${ }^{\circ}$ XLIII, pp. 226-234.

5. F. RUIZ MARTíN, «Movimientos demográficos y económicos en el Reino de Granada durante la segunda mitad del siglo XVI», Anuario de Historia Económica y Social, n. ${ }^{\circ}$ 1, 1968.

6. A.H.PA., Libro de Apeo y Repartimiento de Almería: S.1.3. 
alta de la ciudad ${ }^{7}$, conformando dos barrios de proporciones similares situados en la ladera del monte de la Alcazaba y al pie del cerro de San Cristóbal. El primero tenía como eje la calle de la Morería a la que abrían las tiendas y talleres de los oficiales y comerciantes; el segundo desarrollaba su actividad comercial en la Puerta de Pechina y calle del mismo nombre, llamada de Purchena después de la conquista; otro pequeño núcleo compuesto por ocho familias -los Quevedo- se alineaban en la calle de las Cantarerías, inmediata a la Puerta de la Vega, donde tenían sus casas y oficios de Cantareros. En un trazado urbano enmarañado, casas, talleres y tiendas con puertas a distintas calles, pertenecientes a grupos familiares más o menos extensos, se unen por las espaldas y por los laterales, como formando círculos, quedando separado de este modo lo que es el espacio público y el reservado espacio privado de la vida familiar. De tal manera se halla la familia Albarracín, compuesta por la madre y los hermanos Diego, Luis y Francisco; igualmente están juntas las casas de la madre y los hermanos Luis y Lorenzo Cozulí; Diego y Luis Montanos reúnen en la colación de la Iglesia Mayor tres casas y una tienda.

En el medio rural, las agrupaciones en clanes familiares de casas y haciendas que constituían los barrios y pagos de las alquerías en el momento de la conquista, dando nombre a numerosos topónimos -caso de Benahadux, patronímico que aún se cita a fines del siglo XV en la persona de Alí Abenhaduz ${ }^{8}$, y otros como la hoya del Baho; las acequias de Çafar y de Moquiça; el barranco y pago del Chilichí, el barranco de Yuça Alfax, de Çaid, del Neçi; y el pago o aldea del Marraque en Rioja, nombre que aún perdura-, tras la expropiación de sus tierras y el repartimiento, pierden entidad al pasar a ser propiedad de los cristianos viejos, pero no así las relaciones familiares y de vecindario, al seguir viviendo agrupados -familia extensa- en alguna de sus haciendas de origen, cuya propiedad originaria intentan reconstruir con trueques y compras. Con esta finalidad, en 1564, Martín Mazmudi, el viejo, hace donación a su hijo, Diego Mazmudi, al tiempo de otorgar la carta de dote a Isabel Alaçaraque, de una casa nueva que tenía en una huerta que había comprado a cristianos viejos por 200 ducados, situada junto a la suya en Benahadux, para que vivan allí .

7. No hay datos que confirmen en qué momento se produjo este apartamiento y se constituyó la morería. Esta ya se cita como barrio independiente en el libro del repartimiento; sin embargo, todavía después del terremoto de 1522 hay moriscos que venden sus casas al obispo Villalán para el solar de la nueva catedral. Este cambio en la política de convivencia se ordena en las ciudades de Granada y Baza en 1498 y 1499, y, más tarde, en las Conclusiones del 7 de diciembre de 1526 se dispone de modo exhaustivo las disposiciones que debían aplicarse en el reino de Granada. A. GALlego BuRín y A. GÁMIR SANDOVAL, Los moriscos..., pp. 17, 21, 198-205.

8. C. Segura Graiño, El Libro del Repartimiento de Almería, Madrid, Universidad Complutense, 1982 , ff. 72 y 74, pp. 219 y 223.

9. A. H.P.A., Pr. 69, f. 357. 
En este marco urbano y rural en el que, salvo intereses económicos, rara vez se mezclan cristianos viejos y nuevos, el apego a sus tradiciones da vida a la comunidad morisca, la llamada "obstinación" que tanto crispaba a los cristianos viejos.

\section{LAS RELACIONES FAMILIARES}

Como era típico en la sociedad nazarí, en Almería también existían grandes desigualdades sociales. El linaje más prestigioso lo representaba la familia Venegas ${ }^{10}$, descendiente de los reyes de Granada; su miembro más relevante era don Diego Avis Venegas de Córdoba, llamado en los documentos "el alguacil Abez"; otro patriarca notable era Zulema el Baho, bautizado como don Alonso de Belvis el Babo, primer alguacil mayor de Almería, descendiente de Abdalá Solimán, alfaquí de Almería y secretario del príncipe el Zagal ${ }^{11}$, quien entronca con la familia Venegas al contraer matrimonio con una de las hijas de don Pedro de Granada, doña Brianda de Granada Venegas. Otros miembros prestigiosos de este linaje serán Diego López Abenaxar, Lope Benegas Bedavi, antes Abulhagen, Diego López Haçera ${ }^{12}$ y don Pedro de Belvis.

Desde fechas más o menos tempranas, todos ellos aceptaron la fe cristiana y mantuvieron una estrecha colaboración con las autoridades castellanas. En pago a sus servicios gozaron del favor de los Reyes Católicos, quienes les concedieron ciertos privilegios: exención de hidalguía ${ }^{13}$, cargos públicos en la ciudad y la conservación de gran parte de sus bienes, entre otros. Igualmente muchos de los alguaciles de las alquerías colaboran con los

10. Sobre Yahya al-Nayyar, véase M. ESPINAR MORENO, y J. GRIMA CERVANTES, «Un personaje almeriense en las crónicas musulmanas y cristianas. El infante Cidi Yahya Alnayar (1435-1506): su papel en la guerra de Granada», B.I.E.A, n. ${ }^{\circ}$ 7, 1987, pp. 57-83. Sobre la familia Venegas véase, M. LAFUENTE ALCÁNTARA, Historia de Granada, vol. III y IV, pp. 223-246 y 142-143 respectivamente; L.P. HARVEY, «Yuse Banegas, un moro noble de Granada bajo los Reyes Católicos», Al-Andalus, XXI/2, 1956, pp. 297-302; M. a C. CALERO PAlacios y R. PEINAdo SANTAElla, «Fuentes para el estudio de la nobleza y los señoríos del reino de Granada: el inventario del archivo del Marquesado de Campotejar (1682)», Revista del Centro de Estudios Históricos de Granada y su Reino, n. ${ }^{\circ}$ 1, segunda época, Granada, 1987, pp. 239-260.

11. M. LAFUENTE AlCÁNTARA, Historia de Granada, vol. IV, p. 75.

12. Ver «Memorial de don Francisco Nuñez Muley», en M. GARCÍA ARENAL, Los moriscos, Editora Nacional, Madrid, 1975, pp. 47-56.

13. A. GAMIR SANDOVAL, «Las fardas para la costa granadina. (Siglo XVI). Carlos V (1500-1558)», en Homenaje de la Universidad de Granada, Granada, 1958, pp. 293-330; «Las fortificaciones de la costa sur-oriental del Reino de Granada», en Revista de Historia Militar, 1962, n. ${ }^{\circ}$ 10, pp. 34-36. M.A. LADERO QUESADA, Granada después de la conquista. Repobladores y mudéjares, segunda edición, Granada, 1993, p. 604. 
nuevos dirigentes, entre estos, Alonso de Vargas el Marchaní, alguacil del río y más tarde alguacil de Pechina ${ }^{14}$; Hamete Alhaje o Alhax, ahora Diego de Vargas Alhax, alguacil de Benahadux ${ }^{15}$. Sin embargo, también conservaron los signos de identidad que caracterizaban la estructura de parentesco de la familias moriscas.

\section{LA ENDOGAMIA}

La endogamia, como práctica para mantener su identidad islámica, se repite entre ellos a lo largo de toda la época morisca. Lope Benegas el Vedavi estaba casado con Violante Abenaxer; su hija Violante se unirá a Hernando López Haçera y su hijo, Lope Benegas, el mozo, a Inés Venegas, hermana de don Alonso Venegas de Granada ${ }^{16}$. Los hijos del Baho, por su parte, siguen la misma línea en sus matrimonios: doña Brianda de Belvis Granada Venegas casa con don Diego Aviz de Córdoba; su hijo, Francisco de Belvis el Baho se desposa con Violante de Belvis. De esta manera, la endogamia entre los Venegas, Belvis, Belvis el Baho y Haçera se repite a lo largo del siglo XVI.

Esta misma práctica se observa en los linajes más prestigiosos que poblaban las alquerías del río de Almería. Los alguaciles de Tabernas Alí y Adul Guahid Abudi, ahora Diego y Francisco López de Ayala Abudi ${ }^{17}$, casan con otros linajes ilustres de la zona; así Diego López Abudí era cuñado de Mahomad Abendeud, geliz, ahora llamado Pedro López; su hijo, Íñigo López Aix, es nombrado alguacil de Rioja con 3.000 maravedíes de juro vitalicio ${ }^{18}$; otro miembro de esta familia, García López de Ayala, también alguacil, se casa con Isabel Lodrulí, hija de Diego el Odrule o Lodrulí, otro de los linajes principales de Rioja. Igual ocurre en Alhadra con los Alhodrí, Xarquí y Xergalí, los Vargas Alhax de Benahadux y otros linajes locales. Siempre se casan entre sí, bien con miembros de la misma familia o muy cercanos en sus relaciones.

En los testamentos también es frecuente que marido y mujer tengan el mismo apellido: Martín Xunaymar y Axa, después María Xunaymar, Diego Alhodrí y Juana Alhodrí.

14. M.A. LADERO QUESADA, op. cit., documento n. ${ }^{\circ}$ 82, p. 487.

15. Ibídem, véase la Merced al alguacil de Benahadux, documento n. ${ }^{\circ}$ 117, p. 533.

16. A.H.P.A., Pr. 40, f. 214; Pr. 13:14, febrero, 1531, testamento de doña Violante Abenaxer.

17. A. de la Alhambra, leg. 49-28, f. 2. Citado también por M.A. LADERO QUESADA, op. cit., mercedes a los alguaciles de Tabernas en los documentos n. ${ }^{\circ} 115$ y 116, pp. 529 y 530.

18. Ibidem, p. 600. 


\section{LA ORGANIZACIÓN PATRIARCAL}

La organización patriarcal es otro de los signos de identidad de los linajes moriscos ${ }^{19}$, pero es sobre todo, según M. de Epalza, "la autoridad patriarcal, al interior de las familias, la que más influencia tiene para la defensa del grupo y de sus tradiciones"20.

Al igual que en otros lugares, la familia morisca estaba compuesta básicamente por los padres y los hijos, pero son muchos los casos en los que la familia nuclear tenía a su cargo a los ancianos, a los nietos huérfanos, a algún sobrino, a hermanos o a hijos de un primer matrimonio, dada la frecuencia de segundas nupcias; además, aunque estaba prohibido desde 1526 que tuvieran esclavos, ni otros mozos de servicio, ni criar niños expósitos menores de 15 años, no siempre se cumple esta norma. Las principales familias de Almería debieron de conservar sus esclavos, pues doña Violante Abenaxer, en su testamento otorgado en 1531, da la libertad a Lucrecia, su esclava negra; igual hace Juana Díaz de Abogalib, viuda de Juan Pérez de Çamudio, jurado de la ciudad, y en 1542 libera a su esclava Francisca ${ }^{21}$. En cuanto a los niños, también hay constancia tanto de su crianza como de su aprendizaje en los diversos oficios. En noviembre de 1542, Francisco Alcoçer, padre de huérfanos, entrega a una niña de tres años llamada María, hija de Isabel de Baza, cristiana nueva, a Francisco el Mormaní, especiero, y su mujer Beatriz, para que la críen y les sirva por tiempo de 20 años $^{22}$; María el Gazil, huérfana, entra a servir con Francisco el Motandid ${ }^{23}$; Álvaro de Quevedo, cantarero, cría a Isabel Zumayque, huérfana de Pechina, hasta que la casa con Pedro Hernández, dándole 50 ducados o su valor en ajuar y unas casas junto a la suya para que viva ${ }^{24}$; Hernando el Malah pone de aprendiz a su hijo Luis de 11 años con Francisco Alaxar Montanos, esterero $^{25}$; Marcos de Malpartida, curador de Luis Valdés, huérfano de 7 a 8 años "porque mi padre se fue a Berbería y a mi madre la mataron los moros", lo pone de aprendiz con García Daguan, cantarero, para que lo sirva y aprenda su oficio ${ }^{26}$. Es evidente que el apartamiento de los niños moriscos de sus familias o entorno social para doctrinarlos no se cumple con rigor en Almería.

19. J. CARo Baroja, Los moriscos del Reino de Granada, Madrid, 1976, p. 118 y ss.

20. Míkel de Epalza, Los moriscos antes y después de la expulsión, Madrid, 1992, p. 93.

21. A.H.PA., Pr. 13, 14-II-1531 y Pr. 38, 5-IX-1542, respectivamente.

22. A.H.PA., Pr. 38.

23. A. H.P.A., Pr.51, f. 91 v.

24. A.H.PA., Pr. 79, 29-IX-1560.

25. A.H.PA., Pr. 64, f. 277.

26. A.H.PA., Pr. Pr. 69, f. 589. 
La autoridad patriarcal dirigía la vida del grupo familiar; de tal manera, casaba a los hijos y demás parentela, velaba por la integridad del linaje y disponía el reparto de la herencia. Los hijos estaban obligados a obedecer y honrar a sus mayores, tal y como dice Martín el Mozmudí en su testamento: "Me han servido con aquella fidelidad que hijos virtuosos están obligados a su serviçio" 27 . Cualquier transgresión a la voluntad paterna se penaba con el apartamiento de la familia; con esta finalidad Hernando Alazcar y María el Ramí, vecinos de Santa Fe, otorgan testamento en enero de 1550, saltándose todas las mandas religiosas y otras disposiciones, con el único objetivo de desheredar a su hijo Francisco "porque el suso dicho nos ha sido muy desobediente e porque se casó con Lucrecia Moxacarí, vecina de Huechen, la qual esta cargada de hijos "28.

El celo familiar de la organización patriarcal islámica se refuerza en los momentos difíciles de la sublevación. Un caso significativo es el de Alonso Ortega el Najar, vecino de Vera, quien, en 1569, paga 52 ducados a Juan Ortiz para rescatar de la esclavitud a María, joven de 17 años, natural de Bentarique, porque "es pariente de los parientes del dicho Alonso el Najar y doña Luisa, su mujer $^{29}$.

El reparto de los bienes, según el Derecho musulmán, tenía un carácter igualitario entre los hijos y seguía el orden de los parientes según la línea paterna. En Almería, las donaciones en vida y la herencia parecen ser las formas más extendidas de transmisión de la propiedad, pues la misma dote, en la mayoría de los casos, se considera como adelanto de la herencia. De 26 testamentos recogidos: 6 testadores no tienen hijos y 3 sólo tienen un hijo o un heredero forzoso, 9 reparten sus bienes por igual entre sus herederos y 8 disponen que el tercio de mejora y el quinto de libre disposición, además de la legítima, sean para el hijo o nieto varón primogénito; en esta mejora se suele incluir la casa o hacienda principal donde vive el patriarca.

En algunos casos, dado el grave endeudamiento y el sistema de préstamos al consumo vigente en toda la sociedad almeriense del siglo XVI, esta mejora puede entenderse como una cesión a cambio de cierta ayuda prestada que incluye el crédito y el préstamo. Este es el caso de Juana Díaz de Abogalib, quien declara ciertas ventas de tierras y de la casa en la ciudad donde vive, por favores que su hijo, Juan Pérez de Çamudio el Mozo, le hizo de ciertos pagos, teniendo sus padres necesidad; en otros casos, es simplemente una donación: así Lope Venegas el Bedaví y Violante Abenaxer hacen escritura de donación y de testamento, respectivamente, el mismo día, donando a su hijo Antón Lope Venegas Bedaví el tercio y el quinto de sus bie-

27. A.H.PA., Pr. 82, f. 259.

28. A.H.PA., Pr. 44.

29. A.H.PA., Pr. 1848, f. 18. 
nes, porque se lo habían prometido al tiempo de casar con Isabel Venegas ${ }^{30}$. Esta práctica, que en todos los casos se trata de familias que viven en el ámbito rural o son propietarias de tierras, tiene como finalidad evitar en cierta manera la disgregación de la propiedad familiar y reforzar la autoridad del próximo patriarca, del mismo modo que los Belvis y los Venegas instituyen mayorazgos para mantener unido el patrimonio familiar.

La donación parece estar bastante extendida entre la población morisca y, especialmente, ligada a la condición de la mujer anciana en el ámbito familiar y social, quien sustituye con sus legados y donaciones las escrituras testamentarias.

En unos casos, la donación consiste en un simple reparto de los bienes ${ }^{31}$, pero, generalmente, la donación es una gratificación o mejora a cambio de los servicios prestados ante las dolencias de la vejez y en el mantenimiento del patrimonio familiar del que la mujer es usufructuaria. Así, Isabel Cozaydas, viuda de Francisco Marín, dona a su hijo García Marín la hacienda donde vive en Pechina y la mitad de los frutos que produzca a cambio de que le pague la alcabala y un censo corrido cada año de 10 ducados de principal que tiene $\operatorname{cargados}^{32}$; Isabel Auchala, viuda de Diego de Valencia, dona todas sus heredades en Mondújar a sus hijastros Martín, Alonso y Luis de Valencia, y a su sobrino Fernando Macmin, reservándose también el usufructo y esquilmo "porque soy mujer vieja y no tengo hijos ni quien me sirva y vos me servís y me tenéis en vuestra casa, curándome e sirviéndome, como mi hijo, y la hacienda que os hago donación por no la trabajar de cada día venía a menos" ${ }^{\prime 3}$.

Estas donaciones de la mujer morisca encierran también la solidaridad y el vínculo existente entre los miembros de un linaje, realzando, del mismo modo que en la herencia, a través de la unión entre la tierra y la familia, la autoridad del hijo mayor o el carácter patriarcal de la familia morisca. Un claro ejemplo es la donación que María Nogalte hace a Diego López Abudí, alcalde de Tabernas, al quedar sin descendencia por la muerte de su hijo Francisco Arazjubaya, alegando que "de aqui adelante a de mirar por ella como quienes conforme a su linaje, en remuneraçión dello dende luego le toma por su hijo

30. A.H.PA., Pr. 13. Otros casos son: Leonor Nixarí a su hijo Francisco, Pr. 2, f. 212; Lucas Ydrix a su nieto Martín Ydrix, Pr. 10, f. 27; Juan de Araoz el Gazi a su hijo Antón el Gazi, Pr. 44; Leonor Çaid a su hijo Diego Alhagui, Pr. 51, f. 263; Andrés Dindino a su nieto Andrés Zunbax, Pr. 82; Diego Alhodrí a su hijo Luis Alhodrí, Pr. 48, ff. 62-64 y 73-75.

31. A.H.PA., Pr. 79, f. 150, Lucrecia Moscorrox, viuda de Miguel el Fornay, vecina de Pechina, hace donación a sus hijas María e Isabel Fornay de una huerta pequeña donde vive, reservándose el usufructo mientras viviere.

32. A.H.PA., Pr. 83, 5-IX-1564.

33. A.H.PA., Pr. 65, 10-II-1561. 
e le haze donación de todos sus bienes muebles e raizes", y repite dos o tres veces en su lengua, que "haga con ellos como quienes e del linaje donde viene",34.

Este respeto a los ancianos, que María Nogalte reclama en nombre de su linaje, se mantiene inalterable tanto en las relaciones familiares como en las de vecindario.

\section{RELACIONES DE VECINDARIO}

Los consejos de ancianos siguen reuniéndose en las puertas de las iglesias -antes mezquitasde las alquerías del río para acordar sobre los asuntos que afectan a la comunidad; así consta en 1529 en Huércal y en 1561 en todas las alquerías, para resolver sobre unos conflictos ocasionados en la distribución de las aguas de riego.

La hospitalidad entre vecinos de distintos lugares de la provincia tampoco es extraña, de tal modo lo declara en su testamento Martín Ybca, antes Abrahen, natural de Tabernas, ganadero, quien pasa sus últimos días y muere en casa de Diego Xarquí en Alhadra, a quien deja todos sus bienes ${ }^{35}$.

\section{LA SOLIDARIDAD}

La solidaridad, aunque no exenta de tensiones entre vecinos, es un hecho indiscutible. Ya es conocida la protección que los miembros de los linajes más prestigiosos, colaboradores con los conquistadores, ejercen hacia los moriscos de su comunidad. En Almería, tanto don Diego Avis Venegas de Córdoba y su hijo, don Alonso Avis de Granada Venegas, regidor, como don Alonso de Belvis el Baho y su hijo, Francisco de Belvis el Baho, alguaciles, desempeñan una gran labor como intermediarios entre las clases dirigentes castellanas y la masa morisca, y es muy frecuente encontrarlos en la documentación notarial como intérpretes, fiadores, albaceas de los testamentos y otros asuntos. Pero la defensa del grupo ante las distintas presiones se soluciona entre los mismos vecinos.

Los campesinos moriscos son los que en mayor grado sufren la opresión social a causa de las deudas, pues éstas les llevan a la cárcel hasta que sus familiares o vecinos garantizan unas fianzas suficientes, haciendo "deuda ajena propia”, para saldar el débito. En estas situaciones, a veces, la comunidad morisca muestra estrechas relaciones de vecindario, que hay que interpretar como un signo de solidaridad agnática ante las presiones sociales y

34. A.H.P.A., Pr. 38,22-III-1542, Apéndice documental.

35. A.H.PA., Pr. 2, f. 93. 
ambientales. El 17 de agosto de 1544, a causa de estar preso García el Filabrexí, vecino de Gádor, por cierta cantidad que debía a Lope de Lorenzana y Diego García, mercaderes, comparecen ante el escribano Diego López de Badajoz, ofreciéndose como sus fiadores los siguientes: Andrés Nogalte, Diego el Vice, Francisco el Beni, Diego el Corxofí, vecinos de Mondújar; Martín el Hauxini, de Quiciliana; Diego el Mayorquí, el de las herrerías de Gádor, Francisco Verzocano, Martín el Senesí, Hernando el Maymun, Francisco Mucherí y Alonso Alfahar, alguacil de Gádor, quienes se obligan a pagar para el primer día del mes de marzo del año siguiente un ducado cada uno $^{36}$. Igualmente, en el mismo año, para sacar de la cárcel a Diego Alhocayque y su hijo Antón, de Benahadux, por ciertas cuentas que debían a don Gerónimo de la Cueva, hacen deuda ajena propia por nueve ducados cada uno los siguientes vecinos: Alvaro Zupil, Diego Morux, Martín Abzique, Luis Abzique, Alonso de Almaraz y Martín de Vargas Alhax, hijo del alguacil ${ }^{37}$. En Rioja, en el año de 1556, salen como fiadores de Gómez Zunbax, xarique de Cosme de Quevedo, en cantidad de cinco ducados cada uno: Xayax, Lauxí, Andrés Zutrí, Luis Barcheloní e Isabel, su mujer ${ }^{38}$.

\section{LAS TENSIONES}

Estos mismos lazos de cohesión no impiden que surjan tensiones y afrentas entre vecinos, incluso entre parientes cercanos o familias vinculadas por estrechas relaciones de vasallaje. Estos conflictos, que son normales en cualquier tipo de convivencia, entre los musulmanes responden también a viejas rivalidades entre linajes o a circunstancias problemáticas. Como indica Ladero Quesada, durante la etapa mudéjar y más tarde en el periodo morisco existía "un estado de tensión y desconfianza entre dos comunidades que no se comprenden ni se aceptan de buen grado" 39 . Esta desconfianza, igualmente, se extendía por parte de las dos comunidades al grupo de los colaboradores, siendo especialmente en los primeros años bastante inestable su situación. Como puede observarse en la extensa documentación recogida en la obra de Ladero Quesada, las cartas enviadas por estos mudéjares a los reyes, pidiendo protección, son frecuentes en todo el reino de Granada. En Almería, concretamente, el Marchaní, alguacil de Pechina, a causa de la rebelión de los mudéjares del río, en 26 de octubre de 1499 se queja: "[...] disiendo que por el alcayde mosen Fernando de Cárdenas e Fernando de Trujillo, su hasedor e alcayde del dicho rí, diz que se ha seydo muy agraviado, e, contando el caso, dixo

36. A.H.PA., Pr. 40, ff. 3-15.

37. A.H.PA., Pr. 40, ff. 131 y ss.

38. A.H.PA., Pr. 49.

39. M.A. LADERO QUESADA, op. cit., pp. 281-285. 
quel dicho Fernando de Trujillo por mandado del dicho alcayde diz que le fiso pagar dosientos e quarenta pesantes de plata poco más o menos no deviendo cosa alguna, salvo que, cuando los moros del dicho Rio se rebelaron, fueron todos alborotados a su casa, aviendose el ydo fuyendo a esa çibdad a desir lo que los dichos moros hasyan, e diz que le robaron la dicha su casa e le quemaron todo lo suyo e lo que dentro della tenya de otras personas, e porquel dicho alcayde tenya en las dichas sus casas çierto azeyte e se lo robaron los dichos moros, como todo lo otro que en su casa avia, diz que se lo fizo pagar el dicho Fernando de Trujillo a CLXX maravedies el arroba..." 40.

Juana Díaz de Abogalib también se lamenta de que en el mismo levantamiento de los mudéjares del río, estando sola en el campo con su madre, su hermana y un hermano tullido, "ellas non supieron del dicho levantamiento, nin les plogo dello, antes avían soltado dos judios cativos que tenían porque los dichos moros ge los tomavan e llevavan por fuerça, e a ella amenazavan y las querían matar, diziéndoles de perras moras porque no querían ir con ellos " 41.

Las afrentas familiares, en mayor o menor grado, se suceden a lo largo del siglo XVI, llegándose generalmente, como muestran las cartas de perdón, a un avenimiento que va desde la simple reprimenda a un acuerdo económico para paliar el daño causado. Leonor Dalid, viuda de Martín Dindino, de Huércal, entabla una querella contra Martín Carfi, cuyas familias están emparentadas, por “ciertos malos tratamientos que le había hecho", perdonándole por la intercesión de "buenas personas que se lo han rogado", con condición de que "no le va a hacer mal ni daño ni se atravesará en palabras con ella" "42. Lorenzo Muna de Pechina es avalado por su padre Antón Muna, su hermano Luis y Diego Moreno el Colayche por cierta cuestión que hubo con Luis el Budal y su mujer Brianda Hernández, a cambio de seis ducados y la promesa de que no les molestará a ellos ni a su hacienda "ni se dará a vicios de vino ni se emborrachará",43.

Un extraño percance con resultado de muerte ocurre en Pechina en 1545 entre dos familias principales, los Belvis y los Marchani. En 9 de marzo de 1546, ante el escribano Diego López de Badajoz, Francisco el Marchani y Leonor Abenfarax, junto a sus hijos y hermanos, se avienen con don Alonso de Belvis en otorgar carta de perdón a su hijo, don Pedro de Belvis, regidor, por haber matado a su hijo, Luis el Marchani, "porque están çiertos de no haber tenido el dicho Pedro de Belvis dolo alguno" y ocurrió contra su voluntad, estando una noche "burlando" con las espadas en la rambla que dicen Fum al Purnil y con ellos Diego Almenara Alfax, alguacil de Pechina, cuya muerte le

40. Ibídem, documento, n. ${ }^{\circ} 82$, pp. 487-488.

41. Libro del Repartimiento, f. 18v, p. 111.

42. A.H.P.A., Pr. 69, f. 312.

43. A.H.P.A., Pr. 65 y 79, 10 III-1561. 
ha pesado gravemente, "porque hera muy grande e intimo amigo suyo e de sus padres e todos sus debdos y era tan estrecha la amistad entre el dicho Pedro de Belvis y el dicho Luis el Marchani, que ordinariamente, como amigo e su servidor que era, le tenía consigo e trataba e conversaba con él como tal su amigo". Por tales motivos y también "por razones e intereses que dexan de conseguir por causa de la dicha muerte" y porque han sido requeridos por la justicia de Almería muchas veces, Alonso de Belvis les pagó 270 ducados $^{44}$. No siempre estas reyertas se solucionan con la misma celeridad: durante cuatro años se está querellando Martín Sánchez Hanbril de Benahadux contra la familia Chilichí de Pechina, al acusar a García el Chilichí, mozo de 16 años, de haber sido consorte en la muerte de su hijo Lorenzo Hanbril, perdonándole finalmente a cambio de 60 ducados ${ }^{45}$.

\section{IDENTIDAD CULTURAL}

El tipo de hábitat, la organización patriarcal y los lazos de solidaridad agnática son algunos de los signos de identidad que definen y distinguen a la comunidad morisca como "musulmanes herederos de la vida islámica de al-Andalus" "46, fieles a su religión y a sus tradiciones. Estas diferencias sociales exteriormente se manifiestan en una serie de prácticas culturales, defendidas por Francisco Nuñez Muley como "costumbres antiguas" de los naturales de esta tierra ${ }^{47}$.

Las autoridades castellanas, desde los primeros años de la conquista, intentan borrar cualquier diferenciación externa de raíz islámica mediante sucesivas prohibiciones y represalias, tratando de este modo de dejar caer en el olvido la herencia religiosa y cultural de los moriscos.

El traje morisco es uno de los puntos en el que más insistencia se pone para erradicarlo ${ }^{48}$; sin embargo, tal y como demuestra la iconografía $y$ la documentación, los moriscos siguieron poseyendo ropas y joyas al uso de sus antepasados. Las cartas de dote y arras y los inventarios sobre bienes moris-

44. A.H.PA., Pr. 41.

45. A.H.PA., Pr. 83, ff. 40 y 203.

46. Definición de Míkel de Epalza acerca de ¿qué es ser morisco? Ésta y otras respuestas a esta pregunta se hallan recogidas por B. Vincent en el Estudio Preliminar de la edición facsímil de Los moriscos del Reino de Granada según el Sinodo de Guadix de 1554, p. XXIX.

47. «Memorial de don Francisco Nuúñez Muley», en M. GARCía ArenAl, Los moriscos, Biblioteca de Visionarios, Heterodoxos y Marginados, Madrid, 1975, pp. 47-56.

48. Real Cédula de 20 de junio de 1511; Cédulas de 29 de julio de 1513; Cédulas reales de 23 de febrero y de 1 de julio de 1530; Disposiciones de 1526 de Granada y de 1566 en Madrid. Documentos recogidos en Los moriscos del Reino de Granada según el Sínodo de Guadix de 1554, números XII, XIII, XV, XVI, XXXIV, XXXV, XXXVI. 
cos recopilados por Juan Martínez Ruiz ${ }^{49}$, sobre la base de la documentación existente en el Archivo de la Alhambra, sobre confiscaciones de bienes en el reino de Granada, muestran que las disposiciones castellanas no pudieron doblegar los gustos y los usos tradicionales de los moriscos en su forma de vestir, de engalanarse y de habilitar sus casas.

En Almería, del mismo modo, las cartas de dote registradas en las actas de los escribanos constituyen una fuente inestimable para el estudio de los vestidos, las joyas y el ajuar doméstico de los moriscos, sobre todo teniendo en cuenta que la mayoría de las escrituras son de fecha ya tardía, pues datan de la segunda mitad del siglo XVI. Esta misma reticencia a otorgar escrituras públicas ante notario o escribano a la manera de los cristianos viejos se observa también en los testamentos y debió de ser una práctica extendida en el reino de Granada, pues es uno de los mandatos que se disponen en el Sínodo de Guadix.

Los inventarios de las dotes muestran que, salvo rara excepción, todas las "joyas y preseas", como ellos dicen, que componen el ajuar eran prendas tradicionalmente usadas por el grupo islámico, de las que conservan no sólo las ropas y alhajas sino también, en muchos casos, los nombres específicos de ellas. De tal manera, entre sus vestidos habituales se encuentran: el almayzar, el pelote, la marlota, el fostal, la mingala, la "cala que dizen en arábigo de seda de colores" o una "toca de hlabac con franja de oro". Entre las joyas se enumeran: el collar "que llaman hait en arábigo que tiene dos carçeres de oro e granos de aljófar e çiertas perlas y piedras de color"; otro tipo de collar "que en arábigo llaman miqnin que tiene cinco chapas de oro y los cabos de oro y el campo todo de aljófar", otro tipo de "meqnin de aljófar y campanicas de oro"; un "mecnin de aljófar con seis sexafas e una estrella de oro con sus pinjantes e campanicas de oro"; un apretador de aljófar que llaman nujum; axorcas de aljófar, tutes para las orejas, çabanias, manillas, anillos y estampas de oro y plata. El ajuar lo componen almohadas de lienzo, lino o seda: "de çarçahan de dos caras", "de hiladillo de colores que dicen de gueche”, sábanas redies, la alcatifa, el matrax y otras muchas prendas labradas a la morisca ${ }^{50}$.

La pervivencia de la religiosidad musulmana en los moriscos es otro signo de identidad que se muestra claramente en los testamentos de los cristianos nuevos de Almería.

49. MARTÍNEZ RUIZ, Juan, Inventarios de bienes moriscos del Reino de Granada, Madrid, 1972.

50. Algunas de las cartas de dote del A.H.P.A., son: Pr. 49, 1556, Francisco Zeriate e Isabel de Morales; Pr. 79, del año 1559, f. 131, Julián Xexaf y María Çoraymac; f. 164, Francisco el Vijagui y María Xatah; enero de 1560, Cristóbal de Quevedo y María Xergali; febrero de 1560, Diego Chaguela y Francisca Alfahar; junio de 1560, Luis el Xorvi e Isabel Albixagui; marzo de 1561, Lope Alfahar y Leonor Chiquillo; Pr. 64, 1560, f. 295v., Gerónimo Xabinifix y Leonor Hujux; f. 320, Lope Hanfar y Angela Carfi; Pr. 65, f. 412v, 1561, García Xoaya y Beatriz Najar; Pr. 69, f. 357, 1564, Diego Mazmudi e Isabel Alaçaraque; Pr. 82, julio de 1565, Alonso el Diqse y Angela Çalala. 
Las diferencias urbanísticas que singularizan el marco urbano de las comunidades de los cristianos viejos y nuevos en la Almería del siglo XVI, son a su vez el reflejo de una distinta estructura social, y culturalmente trasciende a la vida temporal y pervive incluso más allá de la muerte. Desde la conquista, los cristianos nuevos se entierran en los cementerios o macaber que estaban habilitados sólo para ellos o en los antiguos lugares sagrados de su religión. Los de la ciudad y las huertas reciben sepultura "en el cimenterio que está vendito junto a la yglesia de la Santísima Trenidad estramuro desta çibdad de Almería" ". Hasta este lugar se extendía el "maqbarat bab Bayyana" musulmán, el cementerio que tomaba el nombre de la puerta próxima, a uno y otro lado del camino que entraba por la Puerta de Pechina ${ }^{52}$. Y es allí donde estuvo la primera fundación del convento de la Santísima Trinidad, próximo a la ermita de San Lázaro, antigua rábita situada al principio de las huertas. Los cristianos nuevos más importantes se enterraban en la Iglesia Mayor ${ }^{53}$, antes la Mezquita Mayor de Almería, mientras que los cristianos viejos yacen principalmente en los monasterios de San Francisco y de Santo Domingo ${ }^{54}$. Los vecinos de las alquerías del río designan como lugar de enterramiento el cementerio del lugar, sus antiguos "maqbarat", junto a las iglesias que habían sido antes mezquitas: Leonor, antes Omalahes, madre del Nixarí, manda ser sepultada "en la rawda donde están mis hijos enterrados" ".

En cuanto al contenido del testamento, en todos los casos tanto el protocolo como las mandas religiosas destacan por su brevedad $\mathrm{y}$ concisión, limitándose a cumplir con los más elementales preceptos religiosos. El apego

51. Isabel Hania (Pr. 2, f. 93); Luis Avencecri, antes Abrahen, (Pr. 2, f. 98); Violante Avenaxer (Pr. 13); Diego López Bahari (Pr. 13, f. 2v); García el Moxaguyt (Pr. 41); Diego Alhodri (Pr. 48, ff. 62-64 y 73-75).

52. L. TORRES BALBAS, «Cementerios hispanomusulmanes», Al-Andalus, XXII, $1 .^{\circ}, 1975$, p. 177. PASQUAL y ORBANEJA: Vida de San Indalecio, pp. 142-143. N. CABRILlANA CIÉZAR, Almería morisca, p. 54. E. MARCos GUILLEN, «Conflictos y lucha de competencias en la arquitectura de la Ilustración: La iglesia de San Sebastián de Almería», en Revista del Centro de Estudios Históricos de Granada y su Reino, n. ${ }^{\circ}$ 2, segunda época, Granada, 1988, pp. 153-164.

53. En la Iglesia Mayor: Juana Díaz de Abogalib (Pr. 38); Beatriz Mormani (Pr. 49). Mencía Gómez en la iglesia de San Juan (Pr. 2, f. 276). María Aliquia Tongia en el cementerio del Hospital (Pr. 13). Francisco Atara en la iglesia de Santiago (Pr. 40, f. 62).

54. D. SEgURA del PINO, «La religiosidad morisca a través de los testamentos», $1 .{ }^{\text {as }}$ Jornadas de religiosidad popular, I.E.A., Almería, 1996, pp. 157-167; «La religiosidad de los primeros repobladores de Almería a través de los testamentos», II ${ }^{a s}$ Jornadas de religiosidad popular, I.E.A., Almería, 1998, en prensa.

55. En Huércal: Leonor Nixari, antes Omalahes (Pr. 2, f. 212); Diego el Parranque (Pr. 11, f. 309). En Alhadra: Leonor Xarqui (Pr. 2. f. 46); Martín Ibca (Pr. 2, f. 98). En Rioja: María Zacaria (Pr. 10, f. 6); María Xumaymar, antes Axa, (Pr. 11, f. 708); Diego el Odrule, Lodrulí, el viejo (Pr. 79, f. 230). En Benahadux: Lucas Ydrix, antes Abdalla, (Pr. 10, f. 27); Leonor Carfi (Pr. 65, f. 516v.); Martín el Mazmudi (Pr. 82); Andrés Dindino el viejo (Pr. 82). En Santa Fe: Hernando Alazcar y María el Rami Pr. 44). En Huéchar: Juan de Araoz el Gazi (Pr. 44). En El Alquián: Leonor Çayd (Pr. 51, f. 263). En Pechina: Leonor López Venegas (Pr. 82). 
a sus tradiciones también se percibe a través de sus declaraciones. La limosna, precepto musulmán, está presente en algunas de las últimas voluntades de los moriscos almerienses. Entre un maravedí y un real oscila la cantidad que mandan en sus legados los cristianos nuevos, especialmente al monasterio de la Trinidad, dedicado a la redención de cautivos, o a la Iglesia Mayor; sin embargo, María Aliquía Tongía se toma la licencia de donar un real a la Iglesia Mayor y un ducado "a quien dixere mis alafias ques pobre por amor de Dios", significativo de que valora más efectivos para el tránsito a la otra vida sus tradicionales rezos que los de la Iglesia católica.

Otros aspectos antropológicos confirman asimismo el arraigo a sus vínculos y la pervivencia cultural de los moriscos almerienses. Los nombres de los moriscos, como puede apreciarse, conservan por lo general el apellido del clan, aunque algunos hagan concesión y usen también el nombre y primer apellido castellano. En cuanto a la lengua, prácticamente en todos los documentos consta la presencia del intérprete, pues ni hablaban el castellano ni lo entendían y mucho menos sabían firmar, salvo en caracteres árabes. De esta práctica generalizada solamente se exceptúan los miembros más jóvenes de las principales familias, que desde los primeros años presentan una sincera aptitud colaboracionista y un intento de sincretismo entre lo morisco y lo castellano. En este orden se observa que un personaje destacado como don Antonio de Córdoba y Valor firma en 1555 en árabe ${ }^{56}$; don Alonso de Belvis el Baho también firma en caracteres árabes, mientras que su hijo Francisco ya en 1554 lo hace en castellano; igualmente don Diego Avis Venegas firma todavía en 1558 en árabe ${ }^{57}$; su hijo, Alonso Avis Granada Venegas, lo hace en castellano ${ }^{58}$.

\section{APÉNDICE DOCUMENTAL}

1542, marzo, 22. Tabernas.

Carta de donación de María Nogalte a Diego López Abudi, alcalde de Tábernas.

A.H.PA., Protocolo n. ${ }^{\text {38, }}$ s. f.

En la villa de Tavernas, jurisdiçión de la noble çibdad de Almería, miércoles veynte y dos días del mes de março, año del nasçimiento de Nuestro Salvador Jesucristo de mil e quinientos e quarenta e dos años. Este día en presençia de mi el escrivano e testigos de yuso escritos e por lengua e interpretaçión de Pedro de Gamez, clérigo e vicario de la dicha villa, estando en las casas de Francisco Razjubaya, difunto, estando allí María Nogalte, su madre, la dicha María Nogalte de su espontánea voluntad e por lengua e in-

56. A.H.PA., Pr. 48, ff. 328-329.

57. A.H.PA., Pr. 59, octubre de 1558.

58. A. MUÑOZ BUENDÍA, «Supervivencia de la población morisca en Almería...». En este estudio el autor incorpora los árboles genealógicos de las familias Venegas, Marín y Bazan. 
terpretaçión del dicho Pedro de Gamez, dixo e otorgó ante mi el dicho escrivano e testigos que adelante se dirán, que por quanto ella tiene mucho amor a Diego López Abudi, allcalde desta dicha villa e le tiene por hijo e lo a criado e sienpre a hecho por ella e por sus hijos e porque de aquí adelante a de mirar por ella como quienes conforme a su linaje, en remuneraçión dello, dende luego le toma por su hijo e le haçe donaçión de todos sus bienes muebles e raizes avidos e por aver quantos ella tiene e le pertenesçen los quales dichos bienes mando porque lo tiene por hijo como dicho es e quiere y es su voluntad que dende luego Diego López Abudi tome los dichos sus bienes muebles e raizes e se apodere de todos ellos y los goze para él e para sus herederos para sienpre jamás por quanto esta es su voluntad de hazer la dicha donación en el dicho Diego López Abudi por las cabsas suso dichas y porque el dicho Diego López haga con ellos como quienes e del linaje donde viene, lo qual dixo la dicha María Nogalte dos o tres vezes por la dicha lengua la qual dicha donaçión le hizo irrevocable, fuerte e firme quanto de derecho se requiere conquel dicho Diego Lópezla alimente e haga con ella como dicho es, como si fuese su madre e guando falleçiere le haga sus esequias como a él le pareçiere lo qual otorgó e firmó con todas las cláusulas e renunçiaçión de leyes e poder a las justiçias que de derecho se requieren e otorgó esta escriptura ante mi el dicho escrivano, como dexava los dichos bienes y los mandava al dicho Diego López porques su hijo y por tal le tomó, siendo presente él. Siendo presente por testigo el dicho Pedro de Gámez que fue el interprete e declaró lo suco dicho a mi el dicho escrivano e Francisco Ortas, jurado de la çibdad de Almería, e Diego de Portillo e Benito de Medina e Pedro de Mendoça, vecinos de la dicha villa, los quales dichos testigos firmaron esta escriptura de sus nonbres por la dicha María Nogalte que a lo suso dicho estuvieron presentes juntamente a mi el escrivano, lo qual se otorgó presente el dicho Diego López Abudi que la açeptó.

\section{RESUMEN}

Los signos de identidad que constituyen la herencia religiosa y cultural islámica de las comunidades moriscas, gracias a un cierto aislamiento, se conservan con bastante integridad en la ciudad de Almería.

A través de las actas notariales de los escribanos almerienses se percibe que, tanto internamente como en sus rasgos externos, los moriscos, acantonados en la morería de la ciudad y desmembradas las agrupaciones clánicas en el campo, rehacen sus tradicionales estructuras familiares y de vecindad, regidas por la organización patriarcal y unidas por estrechos vínculos de solidaridad agnática. Estas diferencias sociales tienen su expresión externa en una serie de prácticas culturales: lengua, onomástica, vestidos, religiosidad, como símbolos de fidelidad y permanencia espiritual.

\footnotetext{
ABSTRACT

The identity signs established by the religious and cultural islamic heritage of Moorish communities, are preserved quite well in Almería tocan, due lo a certain isolation.
} 
Through the scribes'documents found in Almería, we can perceive, both internally and externally, that Moorish people, who were dwelling in the Moorish duarters of the town, and who esplit up into groups belonging to the country clans, remake their traditional family and neighbourliness structures, were governed by the patriarchal organization and closely united by a relationship of "agnática" solidarity. These social differences are expressed externally through a series of cultural practises: such as language, saint's day, clothes and religiousness as symbols of fidelity and spiritual prevalence. 